2006 ERSD Annual Report

DOE-BER Environmental Remediation Sciences Project \# 94639

\title{
Millimeter-Wave Measurements of High Level and Low Level Activity Glass Melts
}

\author{
Dr. Paul P. Woskov \\ Massachusetts Institute of Technology \\ Dr. S. K. Sundaram \\ Pacific Northwest National Laboratory \\ Dr. William E. Daniel, Jr. \\ Savannah River National Laboratory
}

\section{Research Objective}

The primary objectives of the current research is to develop on-line sensors for characterizing molten glass in high-level and low-activity waste glass melters using millimeter-wave (MMW) technology and to use this technology to do novel research of melt dynamics. Existing and planned waste glass melters lack sophisticated diagnostics due to the hot, corrosive, and radioactive melter environments. Without process control diagnostics, the Defense Waste Processing Facility (DWPF) and the Waste Treatment Plant (WTP) under construction at Hanford operate by a feed forward process control scheme that relies on predictive models with large uncertainties. This scheme severely limits production throughput and waste loading. Also operations at DWPF have shown susceptibility to anomalies such as pouring, foaming, and combustion gas build up, which can seriously disrupt operations. Future waste chemistries will be even more challenging. The scientific goals of this project are to develop new reliable on-line monitoring capability for important glass process parameters such as temperature profiles, emissivity, density, viscosity, and other characteristics using the unique advantages of millimeterwave electromagnetic radiation that can be eventually implemented in the operating melters. Once successfully developed and implemented, significant cost savings would be realized in melter operations by increasing production through put, reduced storage volumes (through higher waste loading), and reduced risks (prevention or mitigation of anomalies). 


\section{Research Progress and Implications}

For the past year, as of September 2006 research continued on the development and application of millimeter-wave thermal analysis technology for the advancement of nuclear waste vitrification science and to make possible improved vitrification plant operations. Extensive laboratory work has established the basic configuration of a millimeter-wave sensor for multiple parameter measurements of the molten glass pool in a melter. The basic building blocks are the millimeter-wave heterodyne receiver, a beamsplitter in the receiver field-of-view, a waveguide/optics transmission line to the melt pool, a window to seal the waveguide, and a thermal return reflection (TRR) [1] mirror aligned with the split signal from the beamsplitter. Millimeter-wave signals are both received from, and transmitted to the molten glass. With this configuration, and slight modifications, it is possible to monitor all the melt pool parameters listed in Table 1 using only a single access point into the melter.

Table 1. MMW Measurements

\begin{tabular}{ll}
\hline Parameter & Measured Effect \\
\hline Temperature $(T)$ & Thermal emission \\
Emissivity $(\varepsilon)$ & Reflection amplitude \\
Density $(\rho)$ & Reflection phase \\
Viscosity $(\eta)$ & Reflection phase rate \\
Foaming & Surface \\
& acceleration/emissivity \\
Salt Layer $[2]$ & Emissivity/turbulence
\end{tabular}

The resulting instrumentation was recognized this year with a R\&D 100 Award as one of the most significant technological developments in 2006. The dual receiver thermal analysis instrumentation is shown in Figure 1.

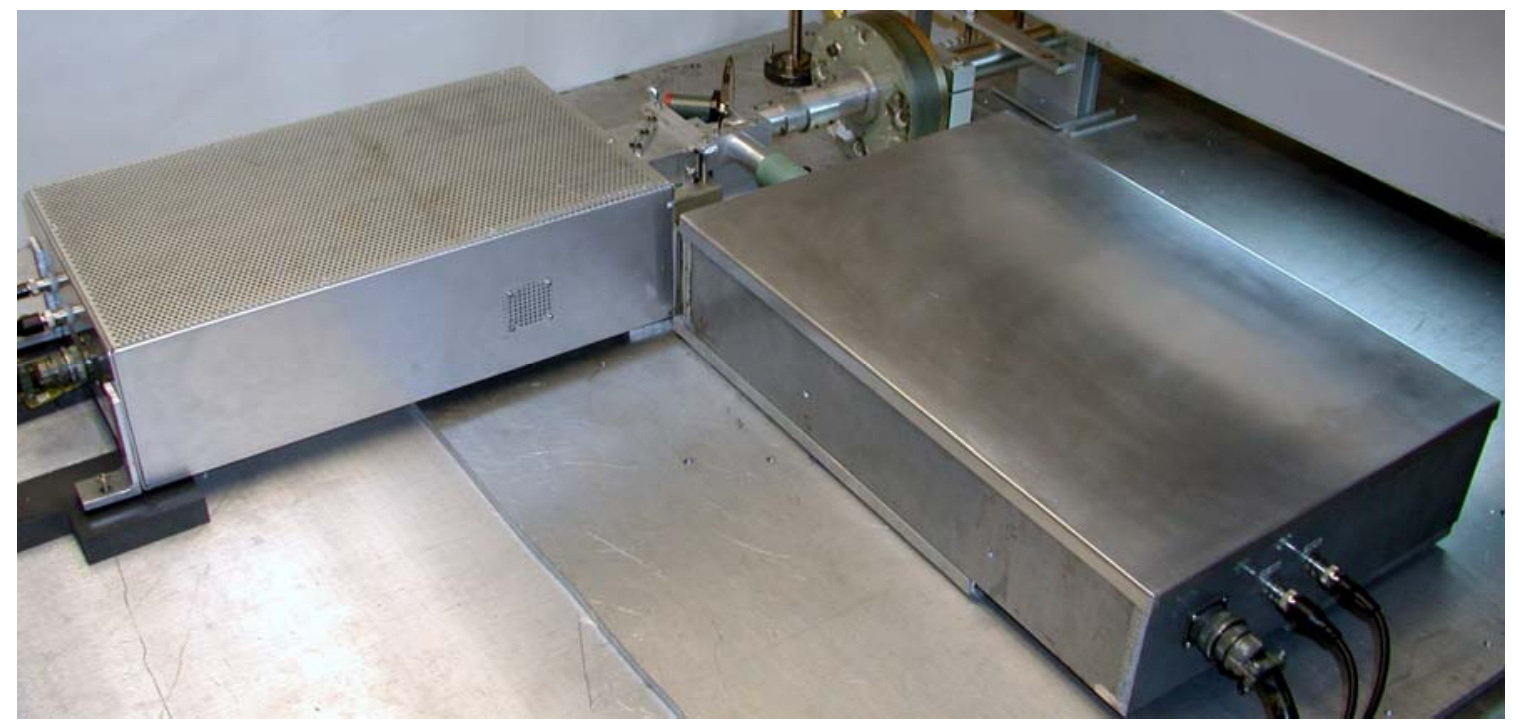

Figure 1. Dual receiver millimeter-wave thermal analysis instrumentation set up on a laboratory furnace at MIT.

This instrumentation captures millimeter waves emitted from the surface of the materials inside a furnace/melter or processing reactor through a "waveguide," a hollow ceramic tube with no moving parts that can withstand the hot, corrosive, and rugged industrial 
environment. One end of the waveguide faces the material surface that is under the processing conditions or that is going through a chemical or physical change. The waveguide guides millimeter-wave thermal emission from the viewed surface, and also guides redirected thermal emission and a coherent millimeter-wave probe signal to the surface for reflection back to the receiver electronics located outside the melter. Two dedicated receivers are used to simultaneously determine temperature and emissivity (a measure of how well a viewed surface emits energy). One receiver measures the passive thermal emission from the material surface for temperature, while the other receiver redirects a portion of the emission signal back at the material surface to monitor an enhanced thermal signal. The ratio of these two signals gives an instantaneous measure of emissivity. Sensitive precision to thermal change is maintained by making the measurements relative to room temperature, and thermal accuracy is achieved by referencing to the known boiling point of liquid nitrogen (hot or cold response of the analyzer relative to room temperature is the same). The physical change or movement of the surface is determined by the coherent probe interference with its reflection, leading to fringes and a fringe pattern shift (similar to the behavior of light waves in a Michelson interferometer).

Data obtained with the MMW dual receiver of the melt dynamics of glass containing salt, is shown in Figure 2. In this data set a sodium ferroaluminosilicate glass (sample ID S22-18) containing about $2 \%$ by weight of sodium sulfate $\left(\mathrm{NaSO}_{4}\right)$ was processed through four heating cycles as shown by the insert temperature plots. Note the difference between the temperature and emissivity behavior that is uniquely observable with the MMW thermal analyzer. The temperature gives a measure of the energy/entropy content, and the emissivity provides an indication of the chemistry/phase state of the glass. In the first heat cycle the initial large drop in the emissivity is due to the first softening of the glass and establishment of a glassy surface. This initial large drop in emissivity is also observed to occur in glass samples without salt. Salt coming out of solution is indicated later in the heating cycle by the high frequency noise structure in the MMW signal and the drop in emissivity below the initial low value. In the subsequent heating cycles, two through four, the high frequency oscillations have mostly disappeared, indicating that the salt has been mostly evaporated away in the first heating.

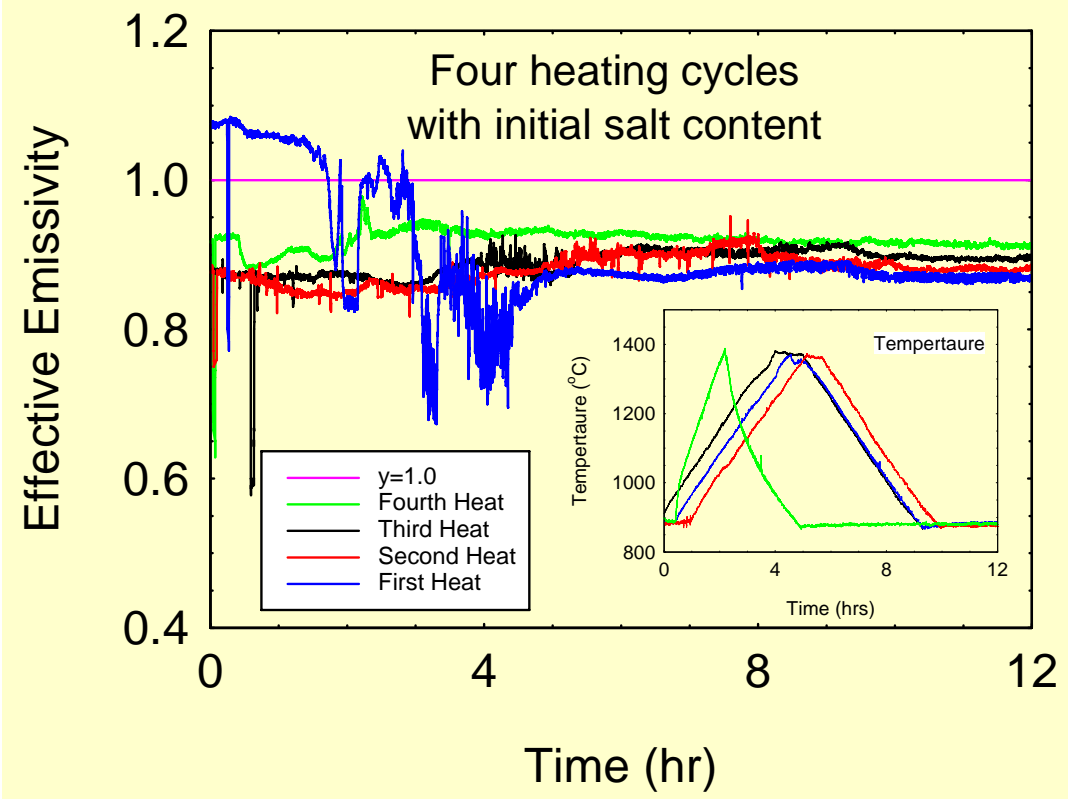

Figure 2. Large decreases in emissivity during the first heating cycle indicate a glass surface forming as the frit melts and salt coming out of solution. 


\section{Implications}

This technology represents a significant advance in thermal characterization and measurement in the field of thermal analysis. Most current thermal measurement technologies rely on thermocouples, sensitive mechanical movement of a microbalance, and near equilibrium conditions. Consequently, the applicability of past thermal analysis and measurement technologies has been limited to the laboratory. Industrial processes, which are often non-equilibrium processes with transients and fluctuations, have been inaccessible. With the availability of the millimeter wave thermal analyzer real processing environments are now accessible. This can lead to important advances in processing efficiencies, quality, and new product development in many industries.

The millimeter wave thermal analyzer instrumentation is a fundamentally new approach to thermal measurement combining electromagnetic waveguide technology with a dualreceiver thermal return reflection (TRR) technology. The TRR was proposed, developed, and demonstrated by this project in the laboratory as well as on a pilot-scale melter. There are no fragile moving parts and the waveguide can be fabricated from robust ceramic materials, which do not need to make contact with the monitored materials. This makes possible, for the first time, on-line thermal analysis, which can be used for monitoring of surfaces, materials, and fluids (e.g., glass and salt melts) in hightemperature and chemically corrosive environments. This novel technology leads to a new paradigm - "take the thermal analysis to the sample, instead of the other way around.” If implemetend at nuclear waste vitrification facilities it would help to reduce virification costs through improved melter operational efficiency and reliablity. This would also contribute to the nuclear energy renaissance by helping to solve the nuclear waste problem. 


\section{Planned Activities}

Funding for this work is being terminated before the originally planned completion date. Testing and analysis of acquired data will continue until the support runs out. This work will include analysis of measurements already obtained, but not yet reduced, to extract as much information as possible from the investment already made. Experiments to tie up loose ends will be carried out as needed. Among the areas where more research development is required are emissivity measurements, density determinations, improved viscosity modeling, and surface curvature and fluctuation effects. New diagnostic capabilities are also needed for liquidus, redox, and plenum gas temperature. Applicability of this unique new technology to other fields will also be pursued.

\section{Information Access}

1. P.P. Woskov and S. K. Sundaram, "Thermal return reflection method for resolving emissivity and temperature in radiometric methods”, J. Appl. Phys., vol. 92, 63026310, 2002.

2. P. P. Woskov, S. K. Sundaram, W. E. Daniel, Jr., D. Miller, "Molten salt dynamics on glass melt using millimeter-wave emissivity measurements”, J. of Non Crystalline Solids, vol. 341/1-3, 21-25, 2004.

3. P. P. Woskov, S. K. Sundaram, G. Daniel, D. H. Miller, "Millimeter-Wave Measurements of Nuclear Waste Glass Melts”, Proceedings IRMMW-THz 2005, Williamsburg, VA, Sept. 19-23, 2005.

4. S.K. Sundaram, P.P. Woskov, W. E. Daniel, Jr., and D. H. Miller, "Millimeter Wave Diagnostics for Vitrification Plants”, Proceedings IRMMW-THz 2006, Shanghai, China, Sept. 18-22, 2006.

5. P. P. Woskov, S. K. Sundaram, W. E. Daniel, Millimeter-Wave Technologies and Techniques for Monitoring High Temperature Processes, Proceedings Asia Pacific Microwave Conference(APMC '04), CD 132.doc, 6 pages, New Delhi, India, Dec 15-18, 2004.

6. P. P. Woskov, S. K. Sundaram, G. Daniel, J. S. Machuzak, P. Thomas, "MillimeterWave Monitoring of Nuclear Waste Glass Melts - An Overview”, Environmental Issues and Waste Management Technologies VII, (Ceramic Transactions, Volume 132) pp. 189-201, 2002 (best paper award American Ceramic Society).

7. "Millimeter-Wave Radiometer Measurement of Emissivity and Temperature by Thermal Return Reflection” P. Woskov, K. Hadidi, S. K. Sundaram, and W. E. Daniel, Jr., International Conference on Infrared and Millimeter-Waves, IEEE 02EX561, 211-212, San Diego, Sept. 22-26, 2002.

8. P. P. Woskov and C. H. Titus, "Graphite Millimeter-Wave Waveguide and Mirror for High Temperature Environments", IEEE Transactions on Microwave Theory and Techniques, vol. 43, 2684-2688, 1995.

9. Paul P. Woskov, Vikram S. Bajaj, Melissa K. Hornstein, Richard J. Temkin, and Robert G. Griffin, “Corrugated waveguide and directional coupler for CW $250 \mathrm{GHz}$ 
gyrotron DNP experiments", IEEE Transactions of Microwave Theory and Techniques, 53, 1863-1869, 2005.

10. P. P. Woskov, D. R. Cohn, D. Y. Rhee, P. Thomas, C. H. Titus, and J. E. Surma, “Active Millimeter-Wave Pyrometer”, Rev. Sci. Instrum., vol. 66, 4241-4248, 1995.

11. P. P. Woskov, S. K. Sundaram, William E. Daniel, Jr.,"Waste Glass Melter Process Monitoring with Millimeter Waves", Spectrum 2002, 9th Biennial Conference on Nuclear and Hazardous Waste Management, American Nuclear Society, 5 pages, Reno, NV, August 4-8, 2002.

12. Paul P. Woskov, K. Hadidi, L. Bromberg, S. K. Sundaram and L. A. Rodgers, Gene Daniel and Don Miller, "Glass Melt Emissivity, Viscosity, and Foaming Monitoring with Millimeter-Waves”, 226h American Chemical Society Meeting CD, Division of Nuclear Chemistry \& Technology, 81, New York, Sept. 7-11, 2003.

13. S. K. Sundaram, P.P. Woskov, J.S. Machuzak, and W.E. Daniel, Jr., “Cold Cap Monitoring using Millimeter Wave Technology", in Environmental Issues and Waste Management Technologies VII, Editors: G. L. Smith, S. K. Sundaram, and D. R. Spearing (Ceramic Transactions, Volume 132) pp. 203-213, 2002.

14. P. P. Woskov, S. K. Sundaram, W. E. Daniel, Jr., D. Miller, J. Harden, "Millimeterwave measurements at $137 \mathrm{GHz}$ of DWPF black frit glass flow and salt layer pooling in a pilot scale melter" 227th American Chemical Society Meeting CD, Division of Environmental Chemistry, 63, psfc.mit.edu/library/04JA001, March 28-April1, 2004. 